\title{
Familial Atypical Hemolytic Uremic Syndrome with Positive pS1191L (c.3572C> T) Mutation in CFH A Single-Center Experience
}

\author{
Fadime ERSOY DURSUN ( $\square$ drfadimeersoy@yahoo.com.tr) \\ Istanbul Medeniyet Universitesi https://orcid.org/0000-0002-3577-188X \\ Gözde YESIL \\ Bezmialem Vakif University school of Medicine, Department of Medical Genetics \\ Hasan DURSUN \\ Okmeydani Traning and researc hospital \\ Gülşah SASAK \\ Istanbul Medeniyet University, School of Medicine Department of Nephrology
}

Research article

Keywords: CFH pS1191L mutation, familial atypical hemolytic uremic syndrome

Posted Date: August 15th, 2019

DOI: https://doi.org/10.21203/rs.2.13028/v1

License: (c) (i) This work is licensed under a Creative Commons Attribution 4.0 International License. Read Full License 


\section{Abstract}

Background: Atypical hemolytic uremic syndrome is a condition characterized by thrombocytopenia, microangiopathic hemolytic anemia, and acute kidney injury, which can exhibit a poor prognosis. Gene mutations play a key role in this disease, which may be sporadic or familial. Methods: We studied, 13 people from the same family were investigated retrospectively for gene mutations of familial atypical hemolytic uremic syndrome after a patient presented to our emergency clinic with atypical hemolytic uremic syndrome and reported a family history of chronic renal failure. Results: The pS1191L mutation in the complement factor $\mathrm{H}$ gene was heterozygous in 6 people from the family of the patient with atypical hemolytic uremic syndrome. One of these people was our patient with acute renal failure and the other two are followed up by the Nephrology Clinic due to chronic renal failure. The other 3 persons showed no evidence of renal failure. The index case had a history of 6 sibling deaths; two of them died of chronic renal failure. Plasmapheresis and fresh frozen plasma treatment was given to our patient. When patient showed no response to this treatment, eculizumab therapy was started. Conclusions: The study demonstrated that a thorough family history should be taken in patients with atypical hemolytic uremic syndrome. These patients may have familial type of the disease and they should be screened genetically. Eculizumab should be the first choice in the treatment with plasmapheresis. It should be kept in mind that the use of eculizumab as prophylaxis in post-transplant therapy is extremely important for prevention of rejection.

\section{Background}

Hemolytic uremic syndrome (HUS) is a type of thrombotic microangiopathy (TMA) characterized by thrombocytopenia, acute kidney injury (AKI), and microangiopathic hemolytic anemia [1, 2, 3]. Atypical HUS (aHUS) accounts for about 5-10\% of all HUS cases and often leads to irreversible kidney injury, often with a worse prognosis [1, 2, 4]. Atypical HUS cases can be categorized as sporadic or familial. Familial aHUS is defined as diagnosis of at least two aHUS cases in the same family over the past six months [3]. Familial aHUS cases account for $20 \%$ of all aHUS patients [5].

Genetic disorders such as gene mutations, rare variants, and risk haplotypes in familial aHUS and sporadic aHUS cases; developmental anomalies such as factor $\mathrm{H}$ against autoantibodies are found in $70 \%$ of patients [6]. The Regulator of Complement Activation gene cluster on human chromosome 1q32 spans over a total of $21.45 \mathrm{cM}$ and contains more than 60 gene codes, 15 of which are complement regulators. This code plays a vital role for both soluble and transmembrane proteins in regulating complement activity. These complement genes are arranged in tandem within two groups. Gene mutations usually occur in complementary genes such as factor $\mathrm{H}$ (CFH), factor I (CFI), factor B (CFB), complement 3 (C3), and membrane cofactor protein (MCP or CD46). Data from familial studies demonstrate that due to a high level of incomplete penetrance of aHUS, $50 \%$ of persons carrying $\mathrm{CFH}$ or MCP mutations do not develop the disease. The genes for $\mathrm{CFH}$ and five $\mathrm{CFH}$ related proteins-CFHR1, CFHR2, CFHR3, CFHR4, and CFHR5 lie in a centromeric $360 \mathrm{~kb}$ segment [7, 8, 9, 10]. Gene mutations and related proteins encoded by these genes play an important role in the course of the disease. Genetic studies in these patients do not include large series. We present a retrospective study on an aHUS patient where genetic screening was performed in family members to diagnose familial aHUS due to the presence of family history of chronic renal failure.

\section{Methods}

The study was carried out at Medeniyet University, Göztepe Training and Research Hospital, Department of Hematology. The first patient presented to our emergency clinic with AKI. The patient was diagnosed as aHUS based on clinical and laboratory evaluations. The patient reported a history of CKD cases in other family members; two of his siblings developed recurrent CKD after they received renal transplantation for CKD; 6 of his siblings died, 3 of whom from CKD, and one uncle of our patient also died from CKD, so gene mutation screening of this family was performed. These results from patient files were retrospectively examined and recorded. Prior to the study, in compliance with the principles of the World Medical Association Helsinki Declaration, a written informed consent to publish was obtained from each family member after they were given detailed explanation about the aims and scope of the study. In the case of children, a written informed consent to publish was obtained from their parent or legal guardian. If the person has died, a written informed consent for publication was obtained from their next of kin. Istanbul Medeniyet University local ethics committee ruled that no formal ethics approval was required in this particular case.

Firstly, the family tree of the patient's family was drawn (Figure 1). Accordingly, 13 individuals from the same family - father and mother of our index case, five siblings, as well as wives and children of two siblings- were included in the study. Previous test results of the family members, including the values of leukocytes, hemoglobin, hematocrit, platelets, glucose, blood urea nitrogen (BUN), creatinine, total protein, albumin, aspartate amino transferase, alanine amino transferase, gamma glutamyl transferase, alkalen phosphatase, lactate dehydrogenase (LDH), total bilirubin, peripheral smear, C3, complement (C4), urine, protein in urine and creatinine, haptoglobin, ADAMTS-13 activity and gene mutation analysis ( $\mathrm{CFH}, \mathrm{CFI}$ and $\mathrm{CD} 46$ gene sequence analysis), were recorded retrospectively from patient files.

\section{Results}


The laboratory findings of 13 patients included in the study are presented in Table 1. The test results of our index case at the time of admission were as follows: hemoglobin $7.8 \mathrm{~g} / \mathrm{dL}$, hematocrit 23.4\%, platelet $56000 \mathrm{~mm}^{3}$, widespread schistocytes in peripheral blood smear, BUN 126 $\mathrm{mg} / \mathrm{dL}$, creatinine $7.8 \mathrm{mg} / \mathrm{dL}$, ADAMTS-13 activity $99.2 \%$, LDH $2350 \mathrm{IU} / \mathrm{L}$ and haptoglobin $<10 \mathrm{mg} / \mathrm{dL}$. Based on these results, the patient was diagnosed with aHUS. Of the 13 patients who were screened, three were diagnosed with CKD, one being our index patient and the other two his siblings. The patient also reported six sibling deaths; two of them died from CKD. Besides, genetic screening results showed that the CFH p.S1191L mutation from the same family was heterozygous (Figure 1 and Table 1).

The family members showing gene mutations included the mother of our index case, three of his brothers and one of his nephews. The laboratory results of these six cases and the other seven family members are shown in Table 1. While all clinical and laboratory findings of the mother, one sibling and this sibling's son were found to be normal, our index patient with heterozygous gene mutation had AKI and his two siblings had CKD. These two siblings was developed recurrent CKD after they received renal transplantation for CKD. They with CKD were still followed up under hemodialysis treatment. Clinical and laboratory results were normal in other 7 patients with negative gene mutation (Table 1). Our index patient was treated with 5 cycles of plasmapheresis and daily fresh frozen plasma therapy, but upon insufficient response to this treatment, Eculizumab therapy was initiated. The patient showed a dramatic improvement after treatment with Eculizumab. The patient's serum creatinine level reduced to $0.8 \mathrm{mg} / \mathrm{dL}$. In the meantime, when the patient was not able to receive Eculizumab treatment for a while, he once again developed AKI, with his blood creatinine level increasing to $6.8 \mathrm{mg} / \mathrm{dL}$. Besides, the patient developed dilated cardiomyopathy as in some cases reported in the literature [11]. Once the patient received Eculizumab therapy on a regular basis, his AKI symptoms and cardiomyopathy began to improve. The results of the test performed on the patient's last admission were as follows: hemoglobin $13.6 \mathrm{~g} / \mathrm{dL}$, hematocrit $40.4 \%$, platelet $345,000 \mathrm{~mm}^{3}$, BUN $48 \mathrm{mg} / \mathrm{dL}$, creatinine $1.8 \mathrm{mg} / \mathrm{dL}, \mathrm{LDH} 210 \mathrm{IU} / \mathrm{L}$, and haptoglobin $18.2 \mathrm{mg} / \mathrm{dL}$. The patient is still followed up by our Departments of Hematology and Nephrology.

\section{Discussion}

Deficiencies in the regulation of the complement system are rather common in atypical HUS, and such deficiencies could be inherited or acquired in nature. In aHUS, patients may be identified as familial or sporadic cases. In inherited cases, genetic mutations in CFH, CFI, C3 convertases, C3 and factor B, thrombomodulin, CD46 and MCP can lead to complement-related HUS. In addition, factors such as deficiency in activity of metalloprotease that cleaves von Willebrand factor (VWF-CP or ADAMTS-13), CFI deficiency, and autoantibodies against CFH may also cause aHUS [12]. This study reports retrospectively scanned results of a family who presented to our center. In six of 13 family members, p.S1191L mutation in the CFH gene was heterozygous. Clinical and laboratory findings detected heterozygous p.S1191L mutation in the CFH gene, while the other three members showed normal clinical and laboratory results. There was no gene mutation or aHUS finding in the other seven family members.

Mutations in the complement genes cause over-activation of the complement alternative route, which results in an excessive increase in C3 and $\mathrm{C} 5$ and the formation of the C5b-9 complex. This complex leads to activation of platelets, endothelial damage, inflammation and the formation of systemic microangiopathic lesions [13]. In this study, the presence of aHUS-related progressive decline in renal function, microangiopathic hemolytic anemia, and thrombocytopenia in one person in the family was attributed to the heterozygous p.S1191L mutation in the CFH gene. The history of CKD and renal transplantation resulting in rejection in two patients was also associated with aHUS that might have occurred as a result of a mutation in this gene. No pathologies were detected in the other three family members with gene mutation, including the mother and a 2-year-old child. Hence, the question arises as to whether factors like female gender, not having experienced a triggering event and young age could serve as protective features in the disease. The absence of any pathological findings in the third family member may have resulted from a mechanism that we cannot explain. There exist studies describing this phenomenon in the literature. Despite heterozygous pathogenic variants in complement genes often identified in diseased and healthy parents, the disease is often sporadic, which indicates that genetic mutations give rise to sensitivity, but they do not cause disease [14]. The disease occurs in approximately $50 \%$ of the family members affected by the gene mutation by the time they reach the age of 45 [13]. This well-established feature of the disease has also been confirmed by our study. In the present study, 3 (50\%) of 6 patients with heterozygous gene mutation developed the disease.

In addition to our index patient, CFH p.S1191L mutation was heterozygous in his two siblings with CKD. These two patients had a history of a deceased-donor kidney transplant, but both developed acute rejection shortly after their transplant surgeries. Both of these patients still receive regular hemodialysis treatment 3 days a week. The fact that other laboratory findings are normal in these patients indicates that no triggering events of aHUS have so far occurred in their life. The diagnosis of aHUS in their siblings and mutations in the CFH gene in the same gene with their siblings suggests that the presence of CKD and rejection after renal transplant in these patients might be associated with their aHUS, but they are not yet in the period of aHUS episodes.

In the treatment of atypical HUS, Eculizumab, a monoclonal antibody that inhibits complement protein C5, has been demonstrated to be an effective treatment option. In recent years, multicentre studies have shown that Eculizumab (Soliris) therapy rapidly improves the platelet count and renal functions in most patients after the first dose, eliminating the need for dialysis and plasma treatment. Eculizumab has been reported to 
be a fast, effective, and life-saving option in the treatment of aHUS $[15,16,17,18]$. Accordingly, we administered Eculizumab therapy to our index patient following plasmapheresis after the first admission. The patient's blood creatinine was reduced from $7.8 \mathrm{mg} / \mathrm{dL}$ to $1.2 \mathrm{mg} / \mathrm{dL}$ through Eculizumab therapy.

\section{Conclusions}

This study identified 6 people who were heterozygous for p.S1191L mutation in the CFH gene in a family of 13 individuals who were genetically screened. While three of these cases showed no aHUS findings, we detected aHUS and CKD in the other three cases, which indicate that the genes have an effect on the disease penetrance by about $50 \%$. A more thorough screening in all relatives of the family could detect a higher incidence of the gene in this family. Failure to diagnose aHUS as a cause of CKD in two individuals of this family during previous follow-up appointments and performing renal transplants before Eculizumab therapy prophylaxis may have caused renal transplant rejection in both patients. This study has therefore revealed that these family members should be closely monitored for early signs and symptoms of aHUS.

\section{Declarations}

Ethical approval; This article does not contain any studies with human participants performed by any of the authors. The article is presented in this paper have not been published previously in whole or part.

Consent for publication: Prior to this study, written consent was obtained from all participants. Written consent was obtained from the parents for the children.

Availability of data and material: The data sets used and/or analysed during the current study are available from the corresponding author on reasonable request.

Competing interests: The authors declare that they have no competing interests.

Funding; No financial support was received for this study

Authors' contributions: Fadime Ersoy Dursun mainly followed and treated patients; Gözde Yeşil performed genetic tests of patients; Hasan Dursun followed pediatric patients and Gülşah Sasak dealt with nephrological problems of patients and followed patients with chronic renal failure

Acknowledgments: We thank Fatih Mehmet Sen for English language editing.

\section{References}

1.Fakhouri F, Zuber J, Frémeaux-Bacchi V, Loirat C (2017) Haemolytic uraemic syndrome. The Lancet 390: $681-696$.

2.Raina R, Krishnappa V, Blaha T et al (2019) Atypical Hemolytic-Uremic Syndrome: An Update on Pathophysiology, Diagnosis, and Treatment. Ther Apher Dial 23: 4-21.

3. Noris M, Remuzzi G (2009) Atypical Hemolytic-uremic Syndrome. N Engl J Med 361: 1676-1687.

4. Moake JL (2002) Thrombotic microangiopathies. N Engl J Med 347: 589-600.

5. Noris M, Caprioli J, Bresin E et al (2010) Relative role of genetic complement abnormalities in sporadic and familial aHUS and their impact on clinical phenotype. Clin J Am Soc Nephrol 5:1844-1859.

6. Dragon-Durey MA, Sethi SK, Bagga A et al (2010) Clinical features of anti-factor H autoantibody-associated hemolytic uremic syndrome. J Am Soc Nephrol 21: 2180-2187

7. Caprioli J, Noris M, Brioschi S et al (2006) International Registry of Recurrent and Familial HUS/TTP. Genetics of HUS: the impact of MCP, CFH, and IF mutations on clinical presentation, response to treatment, and outcome. Blood 108: 1267-1279.

8. Caprioli J, Bettinaglio P, Zipfel PF et al (2001) The molecular basis of familial hemolytic uremic syndrome: mutation analysis of factor $\mathrm{H}$ gene reveals a hot spot in short consensus repeat 20. J Am Soc Nephrol 12 : 297-307

9.Perez-Caballero D, Gonzalez-Rubio C, Gallardo ME et al (2001) Clustering of missense mutations in the C-terminal region of factor $\mathrm{H}$ in atypical hemolytic uremic syndrome. Am J Hum Genet 68: 478-484. 
10. Fremeaux-Bacchi V, Fakhouri F, Garnier A et al (2013) Genetics and outcome of atypical hemolytic uremic syndrome: a nationwide French series comparing children and adults. Clin J Am Soc Nephrol 8: 554-562.

11. Hu H, Nagra A, Haq MR et al (2014) Eculizumab in atypical haemolytic uraemic syndrome with severe cardiac and neurological involvement. Pediatr Nephrol 29: 1103-1106.

12. Ariceta G, Besbas N, Johnson S et al (2009) Guideline for the investigation and initial therapy of diarrhea-negative hemolytic uremic syndrome. Pediatr Nephrol 24: 687-696.

13. Loirat C, Frémeaux-Bacchi V (2011) Atypical hemolytic uremic syndrome. Orphanet J Rare Dis 8: 60.

14. Cody EM, Dixon BP (2019) Hemolytic Uremic Syndrome. Pediatr Clin North Am 66: 235-246

15. Cao M, Leite BN, Ferreiro T et al (2018) Eculizumab Modifies Outcomes in Adults with Atypical Hemolytic Uremic Syndrome with Acute Kidney Injury. Am J Nephrol 48: 225-233.

16. Loirat C, Fakhouri F, Ariceta G et al (2016) HUS International. An international consensus approach to the management of atypical hemolytic uremic syndromein children. Pediatr Nephrol 31:15-39.

17. Merrill SA, Brittingham ZD, Yuan X et al (2017) Eculizumab cessation in atypical hemolytic uremic syndrome. Blood 130:368-372.

18. Ruszkowski J, Heleniak Z, Dębska-Ślizień A (2018) Atypical hemolytic uremic syndrome: a new drug program and first Polish adult patient treated with eculizumab. Pol Merkur Lekarski 45:119-121.

\section{Tables}


Table 1: Laboratory findings of patients

\begin{tabular}{|c|c|c|c|c|c|c|c|c|c|c|c|c|c|c|}
\hline Parameters & ST & DT & $\mathrm{AT}$ & CT & MÜT & NT & MUT & MNT & SA & FT & $\mathrm{AA}$ & ŞA & FA & $\begin{array}{l}\text { Reference } \\
\text { intervals }\end{array}$ \\
\hline Age (year) & 78 & 66 & 28 & 18 & 23 & 26 & 2 & 38 & 30 & 26 & 48 & 12 & 9 & - \\
\hline Gender & $\mathrm{M}$ & F & $\mathrm{M}$ & $\mathrm{M}$ & $\mathrm{M}$ & $\mathrm{M}$ & $\mathrm{M}$ & $\mathrm{M}$ & F & $\mathrm{F}$ & $\mathrm{M}$ & $\mathrm{M}$ & F & \\
\hline $\begin{array}{l}\text { Leukocyte } \\
\left(\mathrm{mm}^{3}\right)\end{array}$ & 8900 & 7600 & 10300 & 5900 & 7870 & 5670 & 19110 & 10500 & 6600 & 7400 & 8200 & 5800 & 7630 & $\begin{array}{l}4000- \\
10000\end{array}$ \\
\hline $\mathrm{Hgb}(\mathrm{gr} / \mathrm{dL})$ & 14.5 & 12.7 & 7.8 & 11.9 & 10.7 & 13.7 & 9.1 & 14.2 & 13 & 14.6 & 13.2 & 12.6 & 12.8 & $13-17$ \\
\hline $\begin{array}{l}\text { Hematocrit } \\
\text { (\%) }\end{array}$ & 43.5 & 38.2 & 23.4 & 36 & 31.6 & 40.8 & 29.3 & 43 & 39.5 & 44.2 & 40 & 38.1 & 39.2 & $37-54$ \\
\hline $\begin{array}{l}\text { Plt } \\
\left(\mathrm{x} 10^{3} \mathrm{~mm}^{3}\right)\end{array}$ & 256 & 368 & 56 & 174 & 120 & 162 & 450 & 210 & 282 & 432 & 342 & 323 & 410 & $150-500$ \\
\hline Urea $(\mathrm{mg} / \mathrm{dL})$ & 32 & 58 & 126 & 113 & 122 & 19 & 23 & 36 & 21 & 25 & 24 & 26 & 21 & $18-55$ \\
\hline $\mathrm{Cr}(\mathrm{mg} / \mathrm{dL})$ & 0.78 & 0.92 & 7.8 & 7.67 & 7.6 & 0.82 & 0.25 & 0.84 & 0.76 & 0.67 & 0.48 & 0.64 & 0.72 & $0.72-1.25$ \\
\hline $\begin{array}{l}\text { T.protein } \\
\text { (gr/dL) }\end{array}$ & 6.8 & 8.2 & 8.1 & 9.13 & 8.6 & 8.2 & 8.2 & 8.1 & 7.9 & 8.2 & 7.8 & 7.2 & 7.5 & $6.4-8.3$ \\
\hline Alb (gr/dL) & 4.2 & 4.3 & 4.4 & 5.1 & 4.4 & 4.7 & 4.29 & 4.4 & 4.6 & 4.8 & 4.1 & 4.0 & 4.3 & $3.5-5.2$ \\
\hline AST (IU/L) & 26 & 38 & 450 & 20 & 24 & 25 & 38 & 35 & 29 & 31 & 36 & 27 & 25 & $<37$ \\
\hline ALT (IU/L) & 24 & 36 & 630 & 6 & 11 & 15 & 18 & 29 & 33 & 36 & 28 & 18 & 21 & $<42$ \\
\hline GGT (IU/L) & 8 & 12 & 14 & 9 & 28 & 14 & 13 & 17 & 29 & 16 & 14 & 12 & 17 & $<64$ \\
\hline ALP (IU/L) & 68 & 58 & 65 & 82 & 123 & 75 & 198 & 59 & 48 & 120 & 110 & 86 & 84 & $<150$ \\
\hline LDH (IU/L) & 243 & 289 & 2350 & 248 & 259 & 213 & 299 & 320 & 252 & 245 & 262 & 246 & 219 & $125-220$ \\
\hline $\begin{array}{l}\text { Glucose } \\
(\mathrm{mg} / \mathrm{dL})\end{array}$ & 86 & 78 & 86 & 99 & 82 & 84 & 108 & 96 & 89 & 78 & 82 & 89 & 74 & $70-105$ \\
\hline $\begin{array}{ll}\text { T. } & \text { bilb } \\
(\mathrm{mg} / \mathrm{dL}) & \end{array}$ & 0.56 & 0.79 & 1.58 & 0.56 & 0.76 & 0.64 & 0.55 & 0.96 & 0.62 & 0.34 & 0.79 & 0.67 & 0.64 & $0-1.2$ \\
\hline Schistocyte & - & + & + & + & + & - & - & - & - & - & - & - & - & - \\
\hline $\mathrm{C} 3(\mathrm{mg} / \mathrm{dL})$ & 134 & 124 & 98 & 95.4 & 136 & 158 & 186 & 124.2 & 154 & 112 & 134 & 142 & 132 & $90-10$ \\
\hline $\mathrm{C} 4$ (mg/dL) & 26.2 & 28.2 & 7.7 & 27.3 & 38.3 & 29.5 & 34.6 & 26.4 & 26.3 & 22 & 24.2 & 23.4 & 21.3 & $10-40$ \\
\hline Proteinuria & - & + & +++ & $\mathrm{NU}$ & $\mathrm{NU}$ & - & + & - & - & - & - & - & - & - \\
\hline Hematuria & - & + & +++ & $\mathrm{NU}$ & $\mathrm{NU}$ & - & + & - & - & - & - & - & - & - \\
\hline $\begin{array}{l}\text { Prot/cr } \\
(\mathrm{mg} / \mathrm{mg})\end{array}$ & $<0.2$ & $<0.2$ & 5.6 & $\mathrm{NU}$ & $\mathrm{NU}$ & $<0.2$ & 0.70 & $<0.2$ & $<0.2$ & $<0.2$ & $<0.2$ & $<0.2$ & $<0.2$ & $<0.2$ \\
\hline $\begin{array}{l}\text { ADAMTS-13 } \\
\text { activity (\%) }\end{array}$ & 97 & 96 & 99.27 & 98.4 & 83.11 & 77.11 & 120.4 & 84.2 & 67 & 94.3 & 88.5 & 92.6 & 102 & $40-130$ \\
\hline $\begin{array}{l}\text { Haptoglobulin } \\
(\mathrm{mg} / \mathrm{dL})\end{array}$ & 16 & 17.3 & $<10$ & 17 & 19 & 18 & 18.3 & 16 & 17.2 & 19.1 & 18.2 & 19.7 & 18.7 & $14-58$ \\
\hline $\begin{array}{l}\text { CFH } \\
\text { p.S1191L } \\
\text { mutation }\end{array}$ & NM & $\mathrm{H}$ & $\mathrm{H}$ & $\mathrm{H}$ & $\mathrm{H}$ & $\mathrm{H}$ & $\mathrm{H}$ & NM & NM & NM & NM & NM & NM & - \\
\hline Outcome & Healthy & Healthy & CRI & CRF & CRF & Healthy & Healthy & Healthy & Healthy & Healthy & Healthy & Healthy & Healthy & - \\
\hline
\end{tabular}


Hgb:Hemoglobin, Plt: Platelets, Alb: Albumin, AST:Aspartate amino transferase, ALT:Alanine amino transferase, GGT:gamma glutamyl transferase, ALP: Alkalen phosphatase, LDH: lactate dehydrogenase, C3:Complement 3, C4: Complement 4, NU:No urine, CFH:Complement factor H, H:heterozigus, NM: no mutation, CRI: chronic renal injury, CRF:chronic renal failure

Figures

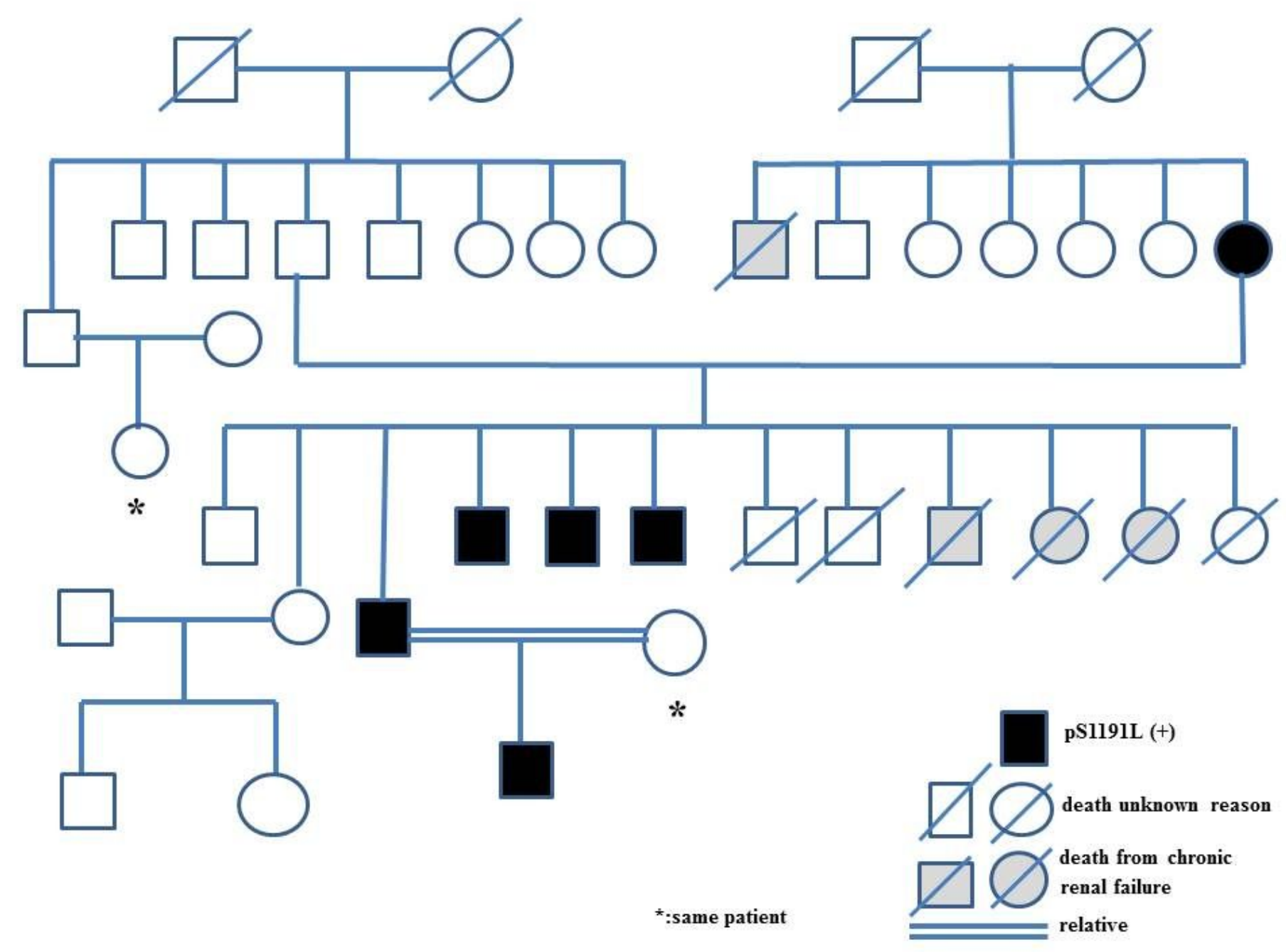

Figure 1

Square symbols represent male family members, and circles represent female family members 